\title{
Impact and persistence of ethical reasoning education on student learning: results from a module-based ethical reasoning educational program
}

\author{
Allison Ames ${ }^{1}$ • Kristen L. Smith ${ }^{1}$. \\ Elizabeth R. H. Sanchez ${ }^{2}$ Lori Pyle ${ }^{3}$ - Tim Ball ${ }^{4}$. \\ William J. Hawk ${ }^{5}$
}

Published online: 20 December 2016

C) Springer International Publishing AG 2016

\begin{abstract}
Ethical reasoning is a teachable skill that college students can (and should) learn (Sternberg 2012). Yet, despite the attention ethical reasoning (ER) education has garnered, institutions have delivered ethical reasoning programs with varied success. Improving students' ethical reasoning skills, and subsequently sustaining those gains throughout the undergraduate career, requires intensive educational curricula delivered over an extended period of time. Specifically, ER instruction should be a program of continuing education rather than a singular or solitary experience (LaGrone et al. 1996). To further examine ethical reasoning education efforts, this study reviewed current practice; piloted a novel, modular-based ethical reasoning program; and studied the new program's efficacy. Results suggest that the program may be effective, having a positive effect on students' lower-level and higher-level ER skills. Yet, only gains in students' lower-level ER skills were sustained for months after they completed the program. The next step is to proceed in continuing to implement additional programs
\end{abstract}

Allison Ames

ames2aj@jmu.edu

1 Center for Assessment and Research Studies, Department of Graduate Psychology, James Madison University, 800 S. Main Street, MSC 6806, Harrisonburg, VA 22807, USA

2 Department of Academic Policy and Curriculum Development, James Madison University, $800 \mathrm{~S}$. Main Street, MSC 6806, Harrisonburg, VA 22807, USA

3 The Madison Collaborative: Ethical Reasoning in Action, James Madison University, 800 S. Main Street, MSC 6806, Harrisonburg, VA 22807, USA

4 School of Communication Studies, James Madison University, 800 S. Main Street, MSC 6806, Harrisonburg, VA 22807, USA

5 The Madison Collaborative: Ethical Reasoning in Action, Department of Philosophy and Religion, James Madison University, 800 S. Main Street, MSC 6806, Harrisonburg, VA 22807, USA 
and curricula that foster the ER skills gained through the educational program. To accomplish this, faculty must continue to teach ER in their courses, coupled with other educational opportunities at the university-level.

Keywords Interactive teaching · Ethical reasoning program · Student feedback · Assessment

Ethical reasoning and decision making are highly desired skills among employers, many of whom consider the abilities "critical to a candidate's potential for career success" (Association of American Colleges and Universities 2013). Publicly played out ethical quandaries, both recent and historical, make it easy to determine why researchers claim ethical reasoning as vital in an individuals' professional and civic lives (Smith 2014). Recent headlines such as Turning Back on Refugees, 'We're in Ethical Free Fall' (Amanpour 2016); Donald Trump's 500 Businesses Would Pose 'Unprecedented Ethical Dilemma' (Goldman 2016); and Donation to Clinton Foundation while Hillary was Secretary of State Violated Ethics Agreement, Report Says (Fox News 2015) come on the heels of the Enron financial scandal in the early 2000s (CNN 2013); the Penn State sexual abuse crimes and questionable integrity in reporting those crimes; an academic fraud, cheating, and plagiarism epidemic (Alschuler and Blimling 1995); and many others. Citizens who are equipped to engage in ethical reasoning and make better decisions when faced with the kinds of ethical scenarios illustrated in news-making situations, and in those less publicized, are needed.

Widespread corruption and misconduct have renewed an interest in colleges preparing students for the ethical dilemmas they will face (Dalton and Crosby 2011). In fact, the Association of American Colleges and Universities (AAC\&U), a national higher education organization, lists Ethical Reasoning and Action as an Essential Learning Outcome. AAC\&U states, “...students should prepare for twenty-first-century challenges by gaining Personal and Social Responsibility including Ethical Reasoning and Action anchored through active involvement with diverse communities and real-world challenges" (The Essential Learning Outcomes 2013).

Fortunately, ethical reasoning is a teachable skill that college students can (and should) learn (Sternberg 2012). Yet, despite the attention ethical reasoning education has garnered, institutions have delivered ethical reasoning programs with varied success. To further examine ethical reasoning education efforts, the researchers of this study reviewed current practice; piloted a novel, modular-based ethical reasoning program; and studied the new program's efficacy.

\section{Review of current ethics education}

Note, several of the studies reviewed in this article focused on moral reasoning rather than ethical reasoning. As cited in Smith (2014), Hawk describes the constructs of moral and ethical reasoning as similar, but not exactly the same. Moral reasoning typically refers to the reflection of societal behavior and norms - what is right, what is wrong. Ethical reasoning refers to analyzing what should be done-what should be right and what should be wrong. Early research and assessment tends to focus more on 
moral reasoning or at least used the term. Moral and ethical reasoning are often used interchangeably, despite their distinctions.

One of the main differences, and novelties, of ethical reasoning education at the researchers' institution is the development of ethical reasoning skills across the curriculum. Typically, ethical reasoning education focuses on developing students' skills whereas traditional ethics education is recall-based, often of theories or professional codes of ethics. Despite these differences, researching the attributes of effective ethics curricula is a starting point for identifying effective ethical reasoning education programs, particularly because a skill-based approach often begins with a general recall of knowledge.

Research into effective ethics curricula is limited; most studies are of individualclassroom programs with small samples. Much of the pre-existing research concerning ethics education has focused on accounting-specific ethics or general ethical reasoning (ER) skills within an accounting classroom. For instance, LaGrone et al. (1996) examined a program within a graduate accounting course that lasted approximately six weeks. Experiment $\left(n_{1}=35\right)$ and control $\left(n_{2}=46\right)$ groups completed an assessment at the beginning of the term (prior to the ethics program), at the end of the term (after the ethics program), and six months after completing the term. Results suggested that the ethics education program fostered the students' abilities to consistently consider ethical issues in their decision-making processes. The researchers suggested that accountants may attain their highest state of ethical awareness if ethics issues are made a part of their continuing education programs, however, gains in moral or ethical development appeared to be transitory (Lagrone et al. 1996).

Following Lagrone et al.'s research, Welton and Guffey (2008) examined whether an ethics program administered during a graduate course in accounting was effective and, if effective, whether the observed moral reasoning gains were transitory or persistent. Students completed the Accounting Defining Issues Test (ADIT) assessment at the beginning of the term prior to the ethics program, at the end of the term, and three years after course completion. Results indicated that gains in moral or ER ability, as measured by the ADIT, are persistent, and are not diminished when students enter the workforce.

In addition, Earley and Kelley (2004) found that gains were made in accountingspecific ethics but not in general ethical reasoning (ER) skills after a 14-week ethics program in an undergraduate accounting course. Together, these findings suggest that an appropriately designed ethics program may influence students' ER, whilst fostering gains in moral reasoning ability, for accounting-specific conceptualizations of the constructs.

In contrast, Ponemon (1993) found a 10-week long program involving videos, lectures, readings, and six four-hour discussions of varied dilemmas prompted no change in ER abilities in undergraduate and graduate accounting students. In a nonaccounting domain, Smith et al. (2004) compared the effects of two different program delivery methods (i.e., written case analyses and written case analyses with group discussion) on ethical issue recognition. The researchers found the educational programs improved students' recognition and assessment of ethical issues in pediatric medicine. Further, the group-discussion component optimized the learning experience and increased students' satisfaction of the program.

A meta-analysis of 55 ER educational program studies published by Earley and Kelley in 2004 was perhaps the most comprehensive study of the effectiveness of ethics education. All of the programs in the study used the Defining 
Issues Test (DIT), which is purported to measure moral judgment. The metaanalysis found the biggest increase of ER assessment scores came from: dilemma discussion, psychological development programs, and programs lasting 3-12 weeks.

Each of these studies appear to affirm Sternberg (2012) in that ER skills can -and should -be taught. However, what constitutes effective ER education is still in the developing stages, as witnessed by the varied results in context-specific ethics programs examined at a classroom (instead of university) level.

Despite mixed research results from existing ethics and ER programs, stakeholders who understood the importance of cultivating students' ER skills at the research setting (hereafter referred to as the University) created and adopted a novel approach to ethical reasoning education and programming by:

- Re-conceptualizing and operationalizing ER as an active process,

- Creating a teachable ER framework that can be used as part of the ethical decision making process

- Developing educational programs aligned with the conceptualization of ER,

- Providing development opportunities to help faculty teach students to engage in the process of ER, and

- Assessing students' ER skills via direct measures that yield psychometrically sound data.

The current study investigates the efficacy of the University's novel approach to ethical reasoning education and programming. First, a description is provided of how ethical reasoning is defined and conceptualized by University stakeholders. Then, student learning outcomes (SLOs), programming, and assessment instruments associated with the nuanced conceptualization of ethical reasoning are discussed. Lastly, assessment data to evaluate the effectiveness of the program and offer recommendations to further improve student learning related to ethical reasoning skills are presented.

\section{A novel Way to define and teach ethical reasoning skills}

At the University, a mid-sized public university in the mid-Atlantic region, a group of university stakeholders agreed that ethical reasoning skill development should be a priority for faculty, staff, and students. Thus, an office on campus, the Collaborative: Ethical Reasoning in Action (ERA), was formed. Stakeholders contributing to the ERA comprise of an ethics expert, crossdisciplinary faculty, student affairs professionals, and assessment specialists. Through an iterative process, the ERA and its stakeholders conceptualized and defined ER differently than previous researchers (see Smith 2014) That is, the stakeholders conceptualized and articulated ethical reasoning as a decision-making process catalyzed by viewing a situation through different perspectives (Smith 2014; Smith et al. 2015) An Eight Key Questions (8KQ) ethical reasoning framework, developed by ERA stakeholders, derived from numerous schools of thought; including those of Aristotle, Kohlberg, Gilligan, 
Kant, Mill, and Rawls, among others (Smith 2014; The Collaborative 2013) The $8 \mathrm{KQ}$ are:

- Fairness: How can I act equitably and balance legitimate interests?

- Outcomes: What achieves the best short- and long- term outcomes for me and all others?

- Responsibilities: What duties and/or obligations apply?

- Character: What action best reflects who I am and the person I want to become?

- Liberty: How does respect for freedom, personal autonomy, or consent apply?

- Empathy: What would I do if I cared deeply about those involved?

- Authority: What do legitimate authorities (e.g., experts, law, my religion/god) expect of me?

- Rights: What rights (e.g., innate, legal, social) apply?

These eight inquiries, representative of differing theories and traditions, are taught to be asked before making a decision. As is supported by social and decision scientists, humans tend to justify or rationalize decisions post-hoc, or after the fact. The Collaborative and those teaching 8KQ on campus are encouraging students to use the inquiry based process to inform, rather than justify, their decisions and actions.

Five cognitive student learning outcomes (SLOs) operationalized the 8KQ learning framework and thus serve as guides for assessing the effectiveness of ER curricula at the University:

1. SLO1: Students will be able to state, from memory, all 8KQ.

2. SLO2: When given a specific decision and rationale on an ethical issue or dilemma, students will correctly identify the KQ most consistent with the decision and rationale.

3. SLO3: Given a specific scenario, students will identify appropriate considerations for each of the $8 \mathrm{KQs}$.

4. SLO4: For a specific ethical situation or dilemma, students will evaluate courses of action by applying (weighing and, if necessary, balancing) the considerations raised by KQs.

5. SLO5: Students will apply SLO 4 to their own personal, professional, and civic ethical cases.

The innovative 8KQ ER framework, along with the five student learning outcomes (SLOs), formed the basis of the University's novel ER programming and curricula. Rather than focusing on one ethical theory or one philosophical school of thought, university stakeholders defined ER via multiple perspectives that encompassed numerous philosophies. The $8 \mathrm{KQ}$ are used as prompts to guide students, faculty, and staff as they actively engage in the ER process.

To ensure faculty have the tools to teach ER as an active decision-making process, the ERA provides various development and training opportunities throughout the calendar year, including a three-hour Introduction to the $8 K Q$ workshop and an ER educational program facilitator training workshop and guidebook. In order to assist in providing students opportunities to learn and actively apply the 8KQ framework, the ERA created two ER program components: 
1) It's Complicated, a 75-min ER educational program that covers SLOs 1, 2, 3, and 4

2) The Collaborative Interactive (MCI): an 8-week, interactive module-based educational program delivered in an online format that also covers SLOs 1, 2, 3, and 4.

Both of these ER curricular components differ from typical ethics education that is characterized by teaching discipline-specific codes of ethics and passive learning (e.g., studying theory) It's Complicated and the MCI are cross-disciplinary in both their content and application. Moreover, both of these programs require active engagement from individual students, while also promoting interactions among students.

\section{Ethical reasoning education programming}

Beginning in fall 2013, all first-year students at the University participate in It's Complicated, an introduction to the $8 \mathrm{KQ}$ delivered as part of orientation programming. During orientation, the entire incoming class (approximately 4380 students for the 2014-2015 academic year) divides into small groups for academic and social programming. For It's Complicated, students are prompted by faculty and staff volunteer facilitators to discuss and analyze a case scenario using the $8 \mathrm{KQ}$. The case scenario and discussion introduces students to a critical thinking method for engaging in ER using the $8 \mathrm{KQ}$, while also creating a common intellectual experience around the $8 \mathrm{KQ}$.

It's Complicated captures the difficulty of making an ethical decision and is the first educational ER program created by the ERA (The Collaborative Learning Activities 2016). Introducing students to the $8 \mathrm{KQ}$ during orientation programming communicates the importance of ER, relays the meaning of each key question, and provides practice identifying the question(s) most relevant to a given scenario. As a result of participating in It's Complicated, students should gain skills relevant to SLOs 1, 2, 3, and 4.

Nonetheless, ERA stakeholders acknowledge that one, 75-min introduction to 8KQ ER at the beginning of students' first-year (i.e., It's Complicated) should be supported by more educational opportunities. The aforementioned research on ER educational programs supports this notion. An additional, longer, ER program: The Collaborative Interactive (MCI) was created as one way to help foster the development of ER skills.

The $M C I$ is an evolving storyline where students vote to determine the general direction of the next episode. This is akin to a Choose Your Own Adventure ${ }^{\circledR}$ story. The eight-episode $M C I$ series, written by faculty members in different disciplines, Mark Piper and Erin Philippi, asks students to reason through various ethical situations using the $8 \mathrm{KQ}$ framework. The story, titled Commencement, takes students on a journey to their first job post-graduation. A shortened version of the week 1 story is presented in Appendix A.

Each episode introduces a new KQ to the storyline and decision-making process. Students need to apply the episode's primary KQ (by writing a short paragraph describing their reasoning), as well as other $\mathrm{KQ}$, to aid them in making their choice. Again, as a result of participating in the $M C I$, students should gain skills relevant to SLOs 1, 2, 3, and 4. A shortened excerpt of the assessment prompt for week 1 is provided in Appendix B. 
Efficacy of ethical reasoning educational curricula The $M C I$ is only one of the education programs targeting ethical reasoning at the University. Starting in fall 2012, the ERA used the assessment tools described in Table 1 to assess students' ethical reasoning skills in relation to the ERA student learning outcomes (SLOs) In addition, the ERA used students' performance on these assessment instruments, as well as student feedback, to evaluate the efficacy of the aforementioned ER curricula (e.g., It's Complicated and the $M C I$ ). Supported by these data, ERA stakeholders are making changes to ER curricula and faculty development opportunities, and subsequently, improving students' ER abilities. Both assessment instruments found in Table 1 [i.e., the Ethical Reasoning - Writing Rubric (ER-WR) and the Ethical Reasoning Identification Test (ERIT)] were developed by University assessment specialists and ERA stakeholders as a quantifiable gauge of ethical reasoning skill development.

Scores on the ER-WR can range from Insufficient (rubric score of 0) to Extraordinary (rubric score of 4) The scores of students who have not experienced It's Complicated nor any other ERA educational program (i.e., baseline scores) have been considered Insufficient as measured by the ER-WR rubric. Scores of first-year students who have experienced It's Complicated have improved to the Marginal (rubric score of 1) range. This lends evidence regarding the promise of It's Complicated to help advance students towards the university's standard of Good (rubric score of 2) on the ER-WR.

Similarly, It's Complicated has shown promise to "move the needle" on the ERIT multiple-choice test, an assessment instrument created to measure students' lower-level (SLO 2 and SLO3) ER skills (See Table 1) That is, students who did not experience It's Complicated or any other ERA curricula scored statistically worse on the ERIT, on average, compared to students who experienced It's Complicated. This evidence indicates that experiencing It's Complicated provides an initial progression towards student achievement of the ER learning outcomes, when compared to baseline scores and is effective in improving students' ER abilities.

While It's Complicated was intended to have the demonstrated initial benefits, more education and opportunities to practice guided ethical reasoning and decision making should help sustain students' higher-level (i.e., SLO4 and SLO5) ER skills as assessed by the ER-WR essay. Certainly, It's Complicated alone will not demonstrably improve students' higher-level ER skills, as measured by the ER-WR; the orientation session is 75 min long and ER skills take practice over time to develop. These findings align with literature regarding effective ER curricula and skill development. The aforementioned assessment results and previous research emphasizing the benefits of additional ER

Table 1 Assessment instruments and alignment with Student Learning Outcomes (SLOs)

\begin{tabular}{|c|c|c|}
\hline Assessment Instrument & Mapping to SLO & Description \\
\hline $\begin{array}{l}\text { Ethical Reasoning - Writing } \\
\text { Rubric (ER-WR) }\end{array}$ & $\begin{array}{l}\text { SLO4 and SLO5 } \\
\text { (higher-level ER skills) }\end{array}$ & $\begin{array}{l}\text { Performance assessment essay prompt } \\
\text { and accompanying analytical rubric; } \\
\text { scored by trained raters }\end{array}$ \\
\hline $\begin{array}{l}\text { Ethical Reasoning Identification } \\
\text { Test (ERIT) }\end{array}$ & $\begin{array}{l}\text { SLO2 and SLO3 } \\
\text { (lower-level ER skills) }\end{array}$ & $\begin{array}{l}\text { 50-item multiple choice test; scored } \\
\text { correct/incorrect }\end{array}$ \\
\hline
\end{tabular}

Reliability and validity evidence for ERIT scores is provided by Smith et al. 2015. Reliability and validity evidence for both ERIT and ER-WR scores is provided by Ames et al. 2016 
educational experiences, emphasizing the need for ER curricula beyond the initial It's Complicated experience.

The process of implementing additional ER curricula is another key distinction of the Collaborative: Ethical Reasoning in Action program: offering workshops targeted towards faculty interested in teaching the 8KQ gives course instructors the tools to implement $8 \mathrm{KQ}$ curricula (and test its efficacy) in individual classrooms. Course level education and assessment then provides an evidence-based platform for generating effective methods of developing ER skills at the course and university levels. University faculty also volunteer to participate in a training of how to use the ER-WR rubric to rate student essays collected during a university-wide assessment day. Rater training involves reading actual student essays, giving faculty the opportunity to see how students reason, and providing insight into the current state of students' ER skills.

\section{Research Questions}

During the spring 2015 semester, the $M C I$ was piloted in a general education communications course, outcomes assessment data were collected using two ERA direct assessment instruments described in Table 1 (i.e., the ER-WR and ERIT), and student feedback was solicited using a closed- and open-ended questionnaire. The current study addresses three research questions related to the $M C I$ module-based ER program:

RQ 1. Is the $M C I$ an effective educational program for teaching students to engage in the ER process? As measured by two of the ERA assessment instruments - the ER-WR and ERIT - students' ER abilities should improve after participating in the $M C I$ program, if the $M C I$ is an effective program for delivering ER skills.

RQ 2. Are gains in students' ER skills sustained after they have completed the MCI? Increased exposure to ER education programs is important for students' ER development. It was hypothesized that three semesters post It's Complicated, students who also completed the $M C I$ would sustain, or further improve, their ER abilities as measured by the ERIT and ER-WR instruments.

RQ 3. What are student perceptions of the $M C I$ educational program? The student experience can be captured not by a single quantitative indicator, but augmented by the breadth and depth of qualitative feedback. Student responses also shape future ER curricula and programming on the University's campus, as well as provide insight into the effectiveness of the MCI educational program.

\section{Methodology}

\section{Participants}

Study participants were identified from the class roster of a general education course taught by a ERA faculty fellow during spring 2015. The class was comprised of freshmen, sophomores, and one senior $\left(n_{\text {total }}=65\right)$ An additional 43 students 
participated in the $M C I$ in order to obtain overall feedback (i.e., non-assessment related) on the $M C I$, such as the usability of web-based platform and time spent on the activity. All participants were at least 18 years of age. Participation was voluntary and participants could withdraw at any time without consequences.

\section{Data collection}

Sixty-five students were administered the ERIT and 41 completed the essay in a longitudinal data collection at two time points: February 2015 and April 2015. This methodology allowed for determination of any immediate gains in ER skills as a result of the MCI program. Approximately one year later, a subset of the same students was re-assessed in February 2016. Specifically, 25 of those 65 were re-assessed on the ERIT and ER-WR in February 2016. Two trained raters independently evaluated and rated each essay using the ER-WR rubric.

Following a re-assessment of students in April 2015, an online Qualtrics survey was administered to consenting students. The survey contained both closed- and openended questions asking students about their experiences with the $M C I$ program and ways to improve future iterations of the $M C I$.

\section{Results}

\section{RQ 1. Is the $M C I$ an effective educational program for teaching students to engage in the ER process?}

Recall, students' ER abilities were assessed via the ER-WR and ERIT assessment instruments (See Table 1) prior to completing the MCI (Pre), immediately after completing the MCI (Post1), and again one year later (Post2) The ER-WR assesses higher-level or more advanced ER skills while the ERIT assesses lower-level or more basic ER skills (see Table 1) Results suggested that students' ER skills were enhanced immediately after completing the $M C I$. That is, the $M C I$ appeared to have an immediate, positive effect on students' lower-level ER skills.

More specifically, to determine the immediate impact of the MCI program, students' pre-test scores were compared to Post1-test scores. As shown in Table 2, the average Post1-test ERIT scores were statistically significantly higher than the average pre-test ERIT scores for $M C I$ students $(t(62)=3.173, p=.002, d=.305)$. That is, students who completed the $M C I$ program demonstrated greater ethical reasoning abilities, as measured by the ERIT, compared to students who did not experience the MCI program, on average;

Table 2 Average pre-, Post1-, and Post2-test in erit total scores across class sections

\begin{tabular}{llll}
\hline & Pre & Post1 & Post2 \\
$\mathrm{N}$ & 63 & 63 & 25 \\
Mean (SD) & $34.33(6.19)$ & $36.22(6.90)$ & $38.00(7.06)$ \\
\hline
\end{tabular}

$M$ Mean, $S D$ standard deviation. PRE refers to students assessed before beginning $M C I$ program. Post1 refers to the same students re-assessed immediately after completing the $M C I$ program. Post 2 refers to students that were re-assessed approximately one year after completing the $M C I$ program 
however, the effect was small to moderate (i.e., on average, $M C I$ participants' scores were about 0.3 of one standard deviation unit higher than non-participants' scores).

As shown in Table 3, on average, students' scores for every element of the ER-WR performance assessment essay rubric were higher after completing the $M C I$ program compared to their scores prior to the $M C I$. The difference was not significant $(t(40)=-$ 1.73, $p=.0916$ ). This suggests that the $M C I$ may not have immediate effects on students' ER abilities as measured by the ER-WR performance assessment rubric.

\section{RQ 2. Are gains in students' ER skills sustained after they have completed the $M C I$ ?}

To determine whether gains in students' ethical reasoning skills were sustained for months after they have completed the $M C I$, a subset of students were assessed approximately one year after they had completed the $M C I$ program (i.e., in spring 2016). Pre-test and Post2-test scores for individuals who participated in the MCI were compared to those who did not participate in the MCI.

A mixed-design ANOVA with ERIT scores (i.e., Pre, Post2) as the within-subjects factor and $M C I$ participation (i.e., either participants who completed the $M C I$ or those who did not complete the $M C I$ ) as the between-subjects factor revealed a significant interaction effect. As shown in Fig. 1, and previously in Table 2, the effect of the passage of time on students' ERIT scores (e.g., from Pre- to Post1-test) depended on whether they had completed the $M C I$ program (i.e. a second intervention; $F(1,298)=$ 4.938, $p=.027, \eta_{p}{ }^{2}=.016$ ).

The significant interaction between $M C I$ participation and ERIT scores indicates that the change from Pre- to post-Post1-test scores on the ERIT was different for $M C I$ participants when compared to non- $M C I$ participants. Although there was little difference between $M C I$ and non-MCI students on their pre-test ERIT scores, after approximately four semesters, the non- $M C I$ students failed to make gains on the ERIT whereas the MCI participants made gains of approximately 2.64 points, on average. That is, students who completed the $M C I$ program ultimately achieved greater gains in their ER abilities from pre-test to Post2-test compared to non-MCI students in the same time period.

Table 3 Average ER-WR revised rubric scores by element

\begin{tabular}{llllllll}
\hline Rubric Element & Pre & \multicolumn{3}{c}{ Post1 } & \multicolumn{3}{c}{ Post2 } \\
& M & $S D$ & M & $S D$ & M & $S D$ \\
Key Question Reference & 1.41 & 0.63 & 1.62 & 0.72 & 1.09 & 0.67 \\
Key Question Applicability & 1.09 & 0.45 & 1.26 & 0.65 & 0.86 & 0.54 \\
Ethical Reasoning: Analyzing individual KQ & 1.09 & 0.53 & 1.40 & 0.81 & 0.84 & 0.69 \\
Ethical Reasoning: Weighing the relevant factors and deciding & 0.90 & 0.50 & 1.07 & 0.64 & 0.77 & 0.50 \\
Overall Average & $\mathbf{1 . 1 2}$ & $\mathbf{0 . 4 8}$ & $\mathbf{1 . 3 4}$ & $\mathbf{0 . 6 5}$ & $\mathbf{0 . 8 9}$ & $\mathbf{0 . 5 6}$ \\
N & 41 & 41 & 25 & & & \\
\hline
\end{tabular}

$M$ mean, $S D$ standard deviation and indicates the spread of scores around the mean. For example, a $S D$ of about 1 on Element B with a mean of about 1 indicates that $68 \%$ of the essays (1SD below and above the mean, assuming a normal distribution) received scores between 0 and 2 . The scale is: $0=$ Insufficient; 1 = Marginal; 2 = Good; 3 = Excellent; and 4 = Extraordinary 


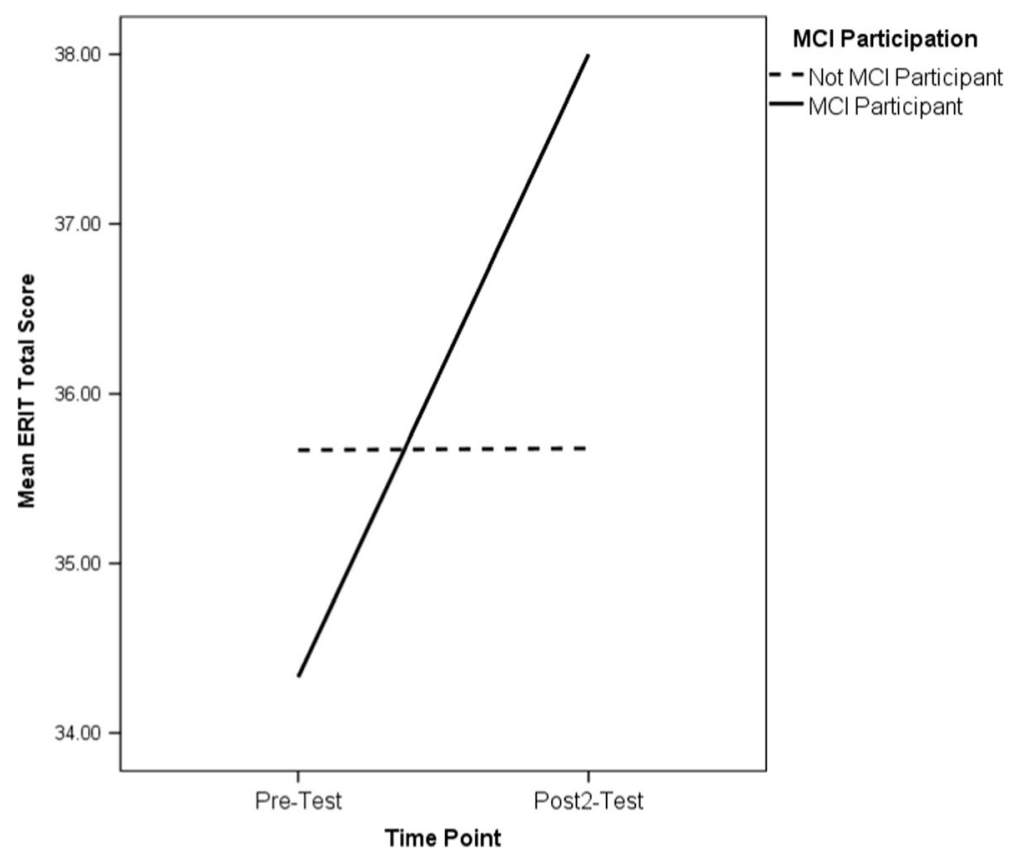

Fig. 1 Pre- and Post2-test ERIT scores for $M C I$ participants compared to non-participants

As shown previously in Table 3, on average, students' scores for every element of the ER-WR were lower one year after completing the MCI (e.g., spring 2016) compared to their scores right after completing the $M C I$ (e.g., spring 2015) This suggests that, on average, initial gains in higher-level skills observed immediately after completing the $M C I$ are not necessarily sustained over the course of the following year. That is, although the $M C I$ appears to be an effective educational program in terms of having an immediate positive effect on students' ER skills, as assessed by the ER-WR, the gains in students' ER skills were not sustained after they completed the MCI program.

As Table 4 shows, before experiencing the $M C I$ program, all students tended to possess similar ER skills as measured by the ERIT (i.e., students had similar ERIT scores). However, students who participated in the $M C I$ demonstrated sustained gains in the ER skills approximately one year after completing the MCI program. Meanwhile, students who did not experience the $M C I$ program did not demonstrate gains in ER skills over time, on average, as assessed by the ERIT. These data suggest that the $M C I$

Table 4 comparison of pre- to Post2-test scores on the ERIT

\begin{tabular}{lllll}
\hline & Non-MCI Participant & & MCI Participants & \\
& Pre & Post2 & Pre & Post2 \\
N & 274 & 274 & 25 & 25 \\
M (SD) & $35.66(6.60)$ & $35.68(7.23)$ & $34.33(6.19)$ & $38(4.6)$ \\
\hline
\end{tabular}

$M$ Mean, $S D$ standard deviation, $N$ sample size. Non-participant students did not receive the MCI, but most likely did received another ER educational program (i.e., It's Complicated) MCI Participants received both the MCI and another ER educational program (i.e., It's Complicated) 
may be an effective educational program for teaching students lower-level ER skills, as measured by the ERIT; as gains have been sustained for months after students have completed the MCI program.

Overall, results suggest the $M C I$ appears to be an effective educational program that had positive effects on students' lower-level and higher-level ER skills (as assessed by the ERIT and ER-WR, respectively). Yet, only gains in students' lower-level ER skills were sustained for months after they completed the $M C I$. Students would likely benefit from additional practice of the newly acquired higher-level skills in order to sustain the gains realized as a result of $M C I$ participation.

\section{RQ 3. What are student perceptions of the $M C I$ educational program?}

Students who completed the $M C I$ program were surveyed concerning their experiences and opinions of the MCI; a total of 43 students responded to closed- and open-ended (i.e., free-response) questions. Researchers utilized student responses to better understand their perceptions of the $M C I$ and incorporate their feedback to improve future content, implementation, and assessment of the $M C I$.

The following presents preliminary results from the student perception survey. Generally, students reported positive experiences with the MCI. In addition, a few students even commented how they enjoyed the way the $M C I$ made them think about ethical reasoning. The most frequent suggestion for improvement was to create stories/ scenarios that were shorter and more targeted or focused rather than to story line "Commencement" (see Appendix A) Also, students suggested incorporating stories that "hit closer to home" for college students.

As is shown in Table 5, students reported that, on average, the number of episodes, the eight weeks' worth of assignments, the amount of time they had to read and respond each week, and the amount of time between episode releases were "about right," with most spending 15-30 min per week on the MCI. Students also tended to report that they thought future $M C I$ students would prefer that the $M C I$ program continue to occur throughout an 8-week time period (i.e., one episode each week).

As part of the online Qualtrics survey, students were asked to what extent they agreed with statements like, "Through my experience with the MCI I feel like ER is an important skill for me to have." Table 6 displays the average ratings across these items. On average, students tended to either Strongly Agree (1) or Agree (2) with all of the statements in Table 6, suggesting that they felt that the $M C I$ had a positive influence on their perceived importance of ER skills and their confidence in their abilities to use the 8KQ. Also, students reported that the $M C I$ experience helped them learn how to use

Table 5 Average rating of duration of MCI 8-episode storyline

\begin{tabular}{llcr}
\hline & Mean & SD & N \\
Number of Episodes (8) & 1.33 & .526 & 42 \\
Eight weeks of assignments & 1.24 & .431 & 42 \\
Amount of time given to read and respond & 1.42 & .545 & 43 \\
Amount of time between episode releases & 1.21 & .514 & 43 \\
\hline
\end{tabular}

$1=$ About right, $2=$ Too many/too long, and $3=$ Too few/too short 
Table 6 Average self-reported learning and attitudes related to the MCI

\begin{tabular}{lll} 
& Mean & SD \\
I feel like ER is an important skill for me to have & 1.67 & 0.75 \\
I learned how to use some of the 8KQ in my own decision making & 2.35 & 0.95 \\
I learned how to determine the "ethically right" thing to do in a situation & 2.40 & 0.93 \\
I learned a skill for making more ethical decisions. & 2.28 & 0.88 \\
I feel confident in my ability to use the eight key questions. & 2.14 & 0.89 \\
\hline
\end{tabular}

$1=$ Strongly Agree, 2 = Agree, $3=$ Neither Agree nor Disagree, $4=$ Disagree, $5=$ Strongly Disagree. $\mathrm{N}=43$

some of the $8 \mathrm{KQ}$ in decision making, determine what is "ethically right," and develop a skill for making more ethical decisions.

As Table 7 shows, on average, students tended to have positive reactions to the format, readability, adequacy of information, and relevancy of the MCI content.

The $M C I$ program was created and delivered through two online software systems: Canvas and WordPress. Students were asked to rate their experiences using these two platforms. On average, students were slightly more satisfied with the Canvas platform $(M=1.57, S D=0.698)$ than the WordPress platform $(M=2.04, S D=1.06)(1=$ Really Happy, 2 = Somewhat Happy, 3 = Indifferent, $4=$ Somewhat Unhappy, $5=$ Really Unhappy) But overall, students reported being somewhat happy or really happy with both platforms.

When asked if they would volunteer to participate in the $M C I$ if it were not part of a class, $74 \%$ of responding students (i.e., 32 students) said they would not volunteer. Following up, students were asked to rank order nine different potential incentives or motivations for participating in the $M C I$. Students rank-ordered from (1) the incentive that would most motivate them to take part in a $M C I$ experience to (9) the incentive that would least likely motivate them. As is shown in Table 8 , on average, students rated "course-related points or credit" as the most motivating incentive. The option of achieving a virtual badge also tended to be ranked fairly highly.

The results indicate that effective delivery of the program required some course requirement to ensure participation and, possibly, adequate motivation.

Recall, one objective was to incorporate student feedback to improve future iterations of the $M C I$ program. Students were asked what changes they would recommend to make the $M C I$ a better platform for learning the $8 \mathrm{KQ}$ approach to ethical reasoning. Approximately $44 \%$ of the students commented that the scenarios/stories should be

Table 7 Average self-reported perceptions of MCI content

\begin{tabular}{lll}
\hline & Mean & SD \\
The evolving story format is an effective way to learn ethical reasoning. & 2.09 & 0.92 \\
The $M C I$ storyline in the episodes held my attention. & 2.49 & 1.16 \\
The episodes were easy to read. & 2.37 & 1.18 \\
Each episode contained enough information to make a decision on the question posed at the end. & 1.91 & 0.84 \\
Each episode was an appropriate length to develop the story and frame the decision. & 2.88 & 1.24 \\
\hline
\end{tabular}

$1=$ Strongly Agree, $2=$ Agree, $3=$ Neither Agree nor Disagree, $4=$ Disagree, $5=$ Strongly Disagree. $N=43$ 
Table 8 Average rankings of potential motivators to participate in the MCI

\begin{tabular}{lll}
\hline Incentive & Mean & SD \\
Course-related points or credits & 1.65 & 1.02 \\
Virtual badge & 2.49 & 1.49 \\
End product (e.g., digital portfolio to be shared with employers) & 4.05 & 1.29 \\
Personal satisfaction & 4.37 & 1.77 \\
T-shirt & 4.56 & 2.05 \\
Service learning element & 5.00 & 1.57 \\
Notation or extracurricular activity list on academic record & 6.19 & 1.26 \\
Other & 7.95 & 0.82 \\
Nothing & 8.74 & 0.49 \\
\hline
\end{tabular}

$N=43$

shorter and more focused ( $N=19$ out of 43). Generally, students conveyed that they thought the stories contained too many extraneous details and would be easier and more enjoyable to read if they were shorter, more focused stories. A little less than $20 \%$ of the students also commented that the scenarios or stories could be more relevant to real life or more interesting to a University student ( $N=7$ out of 43).

Students were also asked what they liked the most and least about the $M C I$. Table 9 displays the five most frequently mentioned "likes" and "dislikes" of the $M C I$ as well as the approximate number of students who mentioned each "like" or "dislike" in their open-ended response.

\section{Selected quotations from students}

"I liked how the episodes dealt with very relatable issues. I know that I have been in tough situations like that and I found it interesting to use those Key Questions to evaluate the situation ethically and reasonably."

Table 9 Average rankings of potential motivators to participate in the MCI

\begin{tabular}{|c|c|c|c|}
\hline $\begin{array}{l}\text { Rank } \\
\text { (Count) }\end{array}$ & Most Liked & $\begin{array}{l}\text { Rank } \\
\text { (Count) }\end{array}$ & Least Liked \\
\hline $1(19)$ & $\begin{array}{l}\text { it was presented as a story and was } \\
\text { interesting, entertaining, relatable, and } \\
\text { applicable }\end{array}$ & $1(24)$ & $\begin{array}{l}\text { stories were too long; irrelevant or } \\
\text { unnecessary information; reading and } \\
\text { responding took too long to complete }\end{array}$ \\
\hline $2(9)$ & $\begin{array}{l}\text { the interactive component; being able to } \\
\text { have a say or an opinion in the story; } \\
\text { being able to state your own voice; being } \\
\text { able to see how the story unfolded each } \\
\text { week }\end{array}$ & $2(6)$ & $\begin{array}{l}\text { stories and response options not realistic } \\
\text { enough; perhaps too superficial }\end{array}$ \\
\hline $3(6)$ & $\begin{array}{l}\text { it made me think; I enjoyed that it made me } \\
\text { learn about/thinking about ethics }\end{array}$ & $3(5)$ & $\begin{array}{l}\text { difficult to keep up with characters; hard to } \\
\text { follow the plot line }\end{array}$ \\
\hline $4(4)$ & boosted my course grade; easy class points & $4(--)$ & --- \\
\hline $5(3)$ & writing was easy to understand; well written & $5(--)$ & --- \\
\hline
\end{tabular}


"I liked how it brought me into a real life situation that could $100 \%$ happen. It brought in drama and a variety of emotions. I felt as though I was actually a part of those situations and trying to solve them the best way possible."

"Considering our class required us to put it in a discussion board- I liked to see what other people said, and what other people interpreted as the ethically right thing to do in any given situation, without the hassle of arguing or attempting to defend your position, as I felt orientation [It's Complicated] had a bit of."

"I liked that it felt vivid and real, it wasn't hard to imagine it was about me."

"There was a lot in each one that could have been cut out and still have had the same effect"

"A lot of it was hard to relate to or seemed superficial."

As a final question on the open-ended portion of the survey, students were asked what kinds of stories they would like to see in future iterations of the $M C I$ program. Approximately $70 \%$ of the students commented that they would like to see stories that are more personal, applicable, or relatable to a current University student. Interestingly, the ERA purposely uses case scenarios that may be a bit unfamiliar to students, faculty, and staff in order to help them reason through the dilemma while minimizing personal bias, especially with initial acquisition of the skills. Nevertheless, students suggested stories that have a college setting or a recent college graduate at a job setting (e.g., issues with professors, roommate problems, dorm drama, parties, etc.; $N=30$ out of 43). Other suggestions for story topics from students included: major-specific or career specific, natural disasters, relationship issues (e.g., started a business with a friend), fantasy or science fiction, family issues, and healthcare.

\section{Selected quotations from students}

"I would like to see the same format of stories but with everyday problems, decisions, and situations that the typical college student comes across."

"I think stories that are more relevant to college students should be used- and I also think that students should be asked two things- what should they do, and what would they do? Anyone would say that you shouldn't cheat, but I see students that do every day. I think [the University] needs to show their students just how poor their morals really are- force them to consider that what they would do is actually wrong."

\section{Conclusions and implications for practice}

Students graduating from college and entering the workforce continue to face ethical dilemmas, and a heightened focus has been placed on ethical decision making by higher 
education bodies (Dalton and Crosby 2011; The Essential Learning Outcomes 2013). Improving students' ethical reasoning skills and subsequently sustaining those gains throughout the undergraduate career requires intensive educational curricula delivered over an extended period of time. Specifically, ER instruction should be a program of continuing education rather than a singular or solitary experience (LaGrone et al. 1996).

Results from the current study suggest that the $M C I$ may be an effective educational program that has positive effects on students' lower-level and higher-level ER skills (as assessed by the ERIT and ER-WR, respectively). Yet, only gains in students' lowerlevel ER skills were sustained for months after they completed the MCI. Therefore, the $M C I$ program can be supported by other ER educational opportunities.

The Collaborative has made tremendous strides towards defining, teaching, and assessing ER skills - the ethical decision-making program is nationally recognized for its content and innovation (e.g., Phi Kappa Phi 2016). Criteria for success of such an ER program include university-wide support, a well-articulated definition of ER through the 8KQ that lends itself to active participation, faculty development and training, and assessment that yields reliable and valid scores and aligns with the ER curricula.

Based on the current research and years of assessment data, the ERA should continue to implement curricula and programming; helping students to cultivate and sustain the higher-level ER skills. As the ERA predicted and findings from the current study suggest, in-depth and repeated practice of ER skills is crucial to sustainable gains in ethical reasoning ability. The next step is to proceed in continuing to implement additional programs and curricula that foster the ER skills gained through It's Complicated and the MCI. To accomplish this, faculty must continue to teach ER in their courses using the $8 \mathrm{KQ}$, and other educational opportunities at the university-level, beyond It's Complicated and the MCI, are needed.

In addition to providing more opportunities for students to develop their ethical reasoning and decision making skills, revisions to the $M C I$ can be made using student feedback and implementation fidelity data. Student feedback regarding time spent on the assignment, web usability, etc. is critical when considering the types of changes that should be made to the $M C I$ while implementation fidelity data may be able to pinpoint precise features of the program that are delivered appropriately and those that require modifications (Gerstner and Finney 2013)

\section{Study limitations}

The study had several limitations, mainly related to sample size and student motivation. One limitation of the current study was that the Post2-test sample only retained 25 of the 65 original respondents. Thus, interpreting and generalizing the findings based on this sample must be done cautiously. Other research found that an intensive week-long faculty development experience was related to improvement in higher-level student learning outcomes, as measured by the ER-WR (Good 2015). However, the curricula piloted as part of this study with the $M C I$ did not necessarily include any faculty development or training components. Thus, future research should examine the effects of the $M C I$ program coupled with targeted, intentional faculty development or training opportunities related to the $M C I$, the $8 \mathrm{KQ}$, and the ERA. In addition, the $M C I$ pilot and data collection was limited to one general education communications course. Future research will need to pilot and examine the effects of the $M C I$ in multidisciplinary contexts. 
One final consideration is that of student motivation on the assessment instruments. On average, the 25 students assessed Post 2 exhibited low importance and effort scores using the Student Opinion Survey (e.g., 14 out of 25 for importance and 19 out of 25 for effort). The levels of student motivation were likely different for the low-stakes Post2 assessment, because, students were given course credit for the Pre- and Postassessment and were likely more motivated to provide high quality responses. Future research regarding possible interventions should ensure adequate student motivation so that assessment results can be trusted.

\section{Appendix A}

\section{Episode 1: "First Things First"}

The alarm goes off, but you've been awake for an hour at least for your first day of work. You have plenty of time so you slow down and try to enjoy getting ready for work. The water runs and your mind turns back to commencement last May, and even further, to your time at college. And now here you are. On the doorstep of the real Commencement. Your first day in the work world. Hard work and some luck have landed you an entry position in a company within your area of study.

Out of the shower, drying off and thinking about what you still have to do, you think that you are missing something, but you push the thought away. You need to take care of a few more things before leaving, but there's still plenty of time. You finish getting dressed, admire your reflection, and take another sip of coffee. All is well. Until your phone rings and startles you, causing you to spill a good half of your coffee into your lap. Damn! There is no quick-fix; you'll have to change. You close your eyes and take a deep breath. No need to panic. If you leave now, you'll be on time.

You begin to gather your things, and as you do so you remember the phone - you never checked it. It's a text from Mom: "So proud of you! Don't forget to drive Cori to her doctor's appointment before heading to work-you know she's too stubborn to ask. I don't know what that girl would do without you, sweetie! <3 you!"

Unbelievable, simply unbelievable. This is what you had forgotten. Somehow you thought it was next week. You double-check your calendar and it stares you in the face: "Monday - take Cori to doctor."

You have to get to work on time - it's your first day! If you leave now, you can help Cori, but then you will be late to work. Or you can make it to work on time, but then Cori will struggle to make her appointment. Her symptoms have been better lately, but after years of friendship, you know that can change at any time. That uncertainty is why she doesn't like to drive. and why you so regularly serve as her chauffeur. .

You could send her a message explaining why you couldn't come, but you know she will be greatly disappointed that you weren't there to support her. Even though it's not rational and you haven't made any formal plans, you know she's expecting you to come through for her just like you have in the past; after all, this could be the day the doctor declares her MS in remission. Given your employer's itinerary for the daythere's a post-work social event planned, it's highly unlikely that you'll have a chance to catch up with her after the day is done. 
You have two options: either you can. 1. drive Cori to her appointment, and arrive to work late, or. 2. arrive to work on time, and stand up Cori, who is likely expecting you this morning. Of course you can call her and let her know the reason for not arriving, but you know that this will not diminish her sense of disappointment, and chances are that you won't be able to visit her at any point later in the day. You must make a decision.

Use the Key Question about Outcomes, "What achieves the best short- and long-term outcomes for me and all others?" to help you choose. Remember, you are being asked to explore the ethical dimensions of this problem and to then make a choice based on that exploration.

Which option do you choose?

\section{Episode 2: “The Bottom Rung”}

\section{If students select option 1, take Cori to the doctor}

Option 1: You run into the building's lobby, huffing and puffing. The run from the community parking garage might as well have been a marathon. After getting Cori to the doctor's office and situated in the waiting room, getting stuck in traffic, discovering that the company's parking deck was full, and then sprinting the distance to the office from downtown, you're about twenty minutes late at this point.

You glance around the lobby, frantically trying to get your bearings, and finally spy a sign that says something about new employee orientation being down the hall to the right, third door on the left. You dart down the hallway and are greeted at the meeting room door by an administrative assistant who is scowling at a clipboard.

\section{If students select option 2, go to work and not take Cori to the doctor}

Option 2: You can't stop replaying this morning's phone conversation with Cori in your mind. While she claimed that she understood your reasons for not driving her to the doctor, she seemed pretty hurt. The worst part was when she said, "You know what, loser? I always thought you'd be with me when I got the big news from my doctor. You're my best friend. For better or for worse, I thought you'd be around. Now I know that your $401 \mathrm{k}$ is more important than my health."

Cori always fights dirty when she's mad. Whenever she's called you "loser" in the past, she meant it affectionately, as a quirky term of endearment. This is the first time she's meant it as an actual slur. Stomach churning, you try to forget the insult and park your car in the company's parking garage. First day - got to keep it together.

As you make your way down the hall, you wonder if everyone you meet today will be so friendly. That would be a welcome change of pace after your stormy start with Cori. You find the third door and push it open.

\section{Regardless of decision}

You and six other new hires are gathered together in a ground-level conference room. Eventually the hiring manager comes in and begins to review company policies, direct deposit instructions, and health insurance forms. As your manager begins to share this 
anecdote, you notice documents that you hadn't yet seen: one containing a breakdown of new hire salaries and credentials. You are surprised to see notable differences here in both respects. There must have been a serious clerical error. There is no way that you should have seen this. The papers must have been placed in your packet by accident.

Julie is wrapping up her story and preparing to rise. You have a choice to make. You have three options: you can. 1. try to get Julie's attention at once in order to tell her that you have these documents, possibly sharing any concerns that you have about its contents,. 2. speak with Julie privately about it after the meeting, again possibly sharing any concerns you have about the contents, or. 3. hide your knowledge of the documents entirely, and attempt to safely dispose of them as soon as possible? You must make a decision.

Use the Key Questions about Fairness, "How can I act equitably and balance legitimate interests?" and

Outcomes as you consider your decision.

Which option do you choose?

\section{Appendix B: Essay Prompt}

Hobbies Galore is a privately owned company that was started in 1975 by Jon and Joan Blacksmith. Jon and Joan Blacksmith are born-again Christians, and deeply committed to their faith. On their website they include statements about their beliefs and their obligations to their employees and customers.

David Montgomery is a senior vice president with the company. He has been with the company since 1978, when he was hired to be the manager of the second Hobbies Galore store. Montgomery and his partner of 25 years, Rick Cornelius, have been asked to be the Grand Marshals in a gay pride parade in Little Rock. Even though the company prohibits employees from taking part in "public demonstrations in favor of or opposed to a cause," Montgomery, who is godfather to the Blacksmith's oldest son, sought permission from the Blacksmiths to appear in the parade with Cornelius as a celebration of their long-term relationship.

After talking and praying together, the Blacksmiths have sought legal advice from the company's attorney who is a member of their church. They have also consulted with their pastor and other senior leaders in their congregation.

What do you think the Blacksmiths should do about Montgomery's request to participate in the gay pride parade? Please note that you're not being asked to provide advice from a legal or religious perspective; rather, you're being asked to share your thoughts based on your exploration of the ethical dimensions of this particular situation.

You will have $45 \mathrm{~min}$ to compose this essay. Your document should be no fewer than 250 words. For your convenience, you are given a piece of paper that repeats the instructions for this task in more detail. You may refer to this piece of paper throughout this assessment. Additionally, you have been provided with scrap paper. You can use the scrap paper to outline your ideas, brainstorm, or apply any other technique to facilitate your writing.

Please feel free to express whatever opinions you might hold. Your essay will NOT be evaluated on what decision was chosen, but rather the clarity and complexity of the thought process underlying that decision. 


\section{References}

Alschuler, Alfred, and Gregory S. Blimling. 1995. Curbing epidemic cheating through systemic change. College Teaching 43(4): 123-126.

Amanpour, Christine. 2016. Turning back on refugees, 'we're in ethical free fall.' Cable News Network [CNN]. 27 January.

Ames, Allison, Kristen Smith, and Elizabeth Pyburn. 2016. The Collaborative Annual Assessment Report \#3.

Association of American Colleges and Universities. 2013. It takes more than a major: Employer priorities for college learning and student success. https:/www.aacu.org/leap/presidentstrust/compact/2013 SurveySummary. Accessed 19 May 2016.

Cable News Network [CNN]. 2013. Enron fast facts. http://www.cnn.com/2013/07/02/us/enron-fast-facts/. Accessed 19 May 2016.

Collaborative Learning Activities. 2016. Accessed 19 May 2016.

Dalton, Jon, and Pam Crosby. 2011. Core values and commitments in college: The surprising return to ethics and character in undergraduate education. Journal of College and Character 12(2): 1-4.

Earley, Christine, and Patrick T. Kelley. 2004. A note on ethics educational interventions in an undergraduate auditing course: Is there an 'Enron effect'? Issues in Accounting Education 19(1): 53-71.

Fox News Network. 2015. Donation to Clinton Foundation while Hillary was secretary of state violated ethics agreement, report says. http://www.foxnews.com/politics/2015/02/26/clinton-foundation-receivedmillions-while-hillary-was-secretary-state-report.html. Accessed 19 May 2016.

Gerstner, Jerusha, and Sara J. Finney. 2013. Measuring the implementation fidelity of student affairs programs: A critical component of the outcomes assessment cycle. Research and Practice in Assessment 8: 15-28.

Goldman, David. 2016. Donald Trump's 500 businesses would pose 'unprecedented ethical dilemma.' CNN Money, 17 March 2016.

Good, Megan. 2015. Improving student learning in higher education: A mixed methods study. PhD Dissertation.

LaGrone, R. Michael, Ralph E. Welton, and James R. Davis. 1996. Are the effects of accounting ethics transitory or persistent? Journal of Accounting Education. doi:10.1016/0748-5751(96)00022-X.

Phi Kappa Phi. 2016. Excellence in Innovation semifinalists. https://www.phikappaphi.org/about/news/2016 /03/15/phi-kappa-phi-names-semifinalists-for-excellence-in-innovation-award\#.V7z_M5grKUk. Accessed 19 May 2016.

Ponemon, Lawrence. 1993. Can ethics be taught in accounting? Journal of Accounting Education 11: 185209.

Smith, Kristen. 2014. Assessing ethical reasoning skills: Initial validity evidence for the Ethical Reasoning Identification Test. Master's Thesis.

Smith, Sherilyn, et al. 2004. Finding effective strategies for teaching ethics: A comparison trial of two interventions. Academic Medicine 79(3): 265-271.

Smith, Kristen, Keston H. Fulcher, and Elizabeth H. Sanchez. 2015. Ethical reasoning in action: Validity evidence for the ethical reasoning identification test (ERIT). Journal of Business Ethics. doi:10.1007 /s10551-015-2841-8.

Sternberg, Robert. 2012. Teaching for ethical reasoning in liberal education. https://www.aacu. org/publications-research/periodicals/teaching-ethical-reasoning-liberal-education. Accessed 19 May 2016.

The Collaborative: Ethical Reasoning in Action. 2013. Quality Enhancement Plan for the Southern Association of Colleges and Schools Commission on Colleges. Accessed 19 May 2016.

The Essential Learning Outcomes. 2013. Association of American Colleges and Universities. http://www. aacu.org/leap/documents/EssentialOutcomes_Chart.pdf. Accessed 19 May 2016.

Welton, Ralph, and Daryl Guffey. 2008. Transitory or persistent? The effects of classroom ethics interventions: a longitudinal study. Accounting Education 18(3): 273-289. 